Research Article

\title{
Structure Optimization of Rib Drill Pipe Based on Gas-Solid Coupling and Orthogonal Experiment
}

\author{
Jia Li $\mathbb{D},{ }^{1}$ Dongmin Li, ${ }^{1}$ Peisi Zhong $\mathbb{D}^{\circ},{ }^{2}$ Guofang Ma, ${ }^{1}$ Hengxuan Luan, ${ }^{1}$ and Shangfei Xia ${ }^{3}$ \\ ${ }^{1}$ Department of Mechanical and Electrical Engineering, Shandong University of Science and Technology, Tai'an 271019, China \\ ${ }^{2}$ Advanced Manufacturing Technology Center, Shandong University of Science and Technology, Qingdao 266590, China \\ ${ }^{3}$ Department of Mechanical and Electronic Engineering, Zaozhuang Vocational College, Zaozhuang 277800, China
}

Correspondence should be addressed to Peisi Zhong; pszhong@163.com

Received 4 September 2020; Revised 8 November 2020; Accepted 29 November 2020; Published 12 December 2020

Academic Editor: Gang Zhou

Copyright ( $\odot 2020$ Jia Li et al. This is an open access article distributed under the Creative Commons Attribution License, which permits unrestricted use, distribution, and reproduction in any medium, provided the original work is properly cited.

\begin{abstract}
At present, drilling rig is a common equipment for controlling gas outburst generated in underground coal mine, and rib drill pipe is an important component of drilling rig. Due to the insufficiency of slag discharge capacity, pipe-sticking accidents often occur during the drilling process, which greatly reduces the effect of gas control. In order to improve the capacity of slag discharge of rib drill pipe, the mechanism of slag removal was analyzed, and the process of slag discharge was simulated as a gas-solid two-phase flow coupling process. Utilizing the computational fluid dynamics method, the process of slag discharge was simulated on the Edem-Fluent cosimulation platform. The structural parameters of the drill pipe affecting the capacity of slag discharge were derived. Based on the analysis results, the structural parameters of rib drill pipe were optimized by orthogonal experiment method. The global optimal results were obtained as follows: its pitch, blade height, and blade width are $120 \mathrm{~mm}, 3 \mathrm{~mm}$, and $15 \mathrm{~mm}$, respectively. Therefore, the results of slag discharge experiment on the optimum structure of rig drill pipe show that the slag discharge efficiency is increased by $11.38 \%$, which effectively resolves the pipe-sticking problem.
\end{abstract}

\section{Introduction}

Gas outburst and rock bursts are extreme behavior in coal mine which can cause economic losses and severe fatalities [1-5]. Underground coal seam gas drainage is a widely used method for lowering the risk of gas outburst [6-8], and pressure relief drilling is one of the most effective methods to release high stress concentrations and effectively reduce the rock mass volumetric elastic potential energy [9-11]. Both methods need drilling a long distance borehole. Pipesticking is the main factor affecting the process of drilling borehole in soft outburst coal seam, while the coal slag blockage is the main cause of the pipe-sticking. There are many drilling technologies for soft outburst coal seam $[12,13]$, such as hydraulic slag discharge drilling, auger pipe slag discharge drilling, air atomized drilling [14], foam drilling [15], and casing drilling [16]. These drilling technologies can be divided into two categories according to the method of slag discharge: one is by the mechanical force generated from the rotation of the drill pipe, and the other one is by the fluid force. With the increase of drilling depth, the quality of coal slag needed discharge in drill hole would increase. When the torque for coal slag discharge exceeds the coal mine drilling rig's capacity, the drilling work has to pause. So the method of slag discharge by mechanical force will confine the depth of drilling hole [17]. Slag discharge by fluid force is easy to fail, because this method could not dredge by fluid when the discharge channel is blocked [18]. The special structure of the rib drill pipe enables it to discharge slag in two ways, and the slag discharge method of rib drill pipe with fluid has few disturbances to hole wall. It is widely used in drilling borehole for gas drainage in soft outburst coal seam.

At present, the single-phase flow method was mainly used in the study of the method of mechanical-fluid compound slag discharge. This method is limited because it could not fit the process of actual slag discharge completely. In this paper, the slag discharge mechanism of rib drill pipe 
is analyzed. Based on the computational fluid dynamics (CFD) method [19], the Edem-Fluent coupling platform is used to simulate the slag discharge process of rib drill pipe [20-23]. The structural parameters of rib drill pipe are optimized by orthogonal experiment, which provides a solution to the problem of pipe-sticking.

\section{Slag Discharge Mechanism of Rib Drill Pipe}

2.1. Structure of Rib Drill Pipe. As shown in Figure 1, the rib drill pipe is characterized by a hollow pipe with blade structure. Compared with traditional auger drill pipe, rib drill pipe has the two advantages: one is that the hollow part in the middle is big enough for fluid to pass through; the other one is that the height of blade is low, so the obstruction to fluid is little.

2.2. Slag Discharge Mechanism of Rib Drill Pipe. In the process of horizontal drilling, the rib drill pipe produces coal slag by the drill bit. The slag discharge channel is shown in Figure 2. First, the compressed airflow enters the inlet channel and gets to the bottom of drill hole. Second, the airflow mixes with the coal slag at the bottom to make them suspended. Finally, under the agitation of the rib drill pipe blade, the coal slag is transported outward from the annular channel formed between the outer surface of the drill pipe and the hole wall [24]. In the process of slag discharge, the rotating motion of blade can prevent the coal slag from being deposited at the below place of the drill hole, so that the coal slag and the high-speed airflow can always be fully mixed. When collapse occurs in a position of the drill hole and the slag discharge channel is blocked, the airflow is stopped and the fluid slag discharge method fails. The blade of the rib drill pipe has the capacity of mechanical slag discharge, which can slowly discharge the coal slag in the blocked position and dredge the slag discharge channel until the fluid slag discharge recovers. The rib drill pipe has both fluid and mechanical slag discharge methods, and its slag discharge ability is relatively stronger than other type drill pipe. Therefore, the employ of rib drill pipe can effectively improve the rate and depth of hole formation [25].

\section{Slag Discharge Model of Rib Drill Pipe}

3.1. Model of Rib Drill Pipe. According to the slag discharge process, the three dimensional (3D) model of rib drill pipe is established. We take a common rib drill pipe as the research object and measure it. The structural parameters of the drill pipe are shown in Table 1.

Considering the computational efficiency of computer, this paper took single drill pipe as the research target and simplified the bit. In order to simulate the slag discharge process of drill pipe in the drill hole, a hole space model matched with the drill pipe was established. The diameter of drill hole is generally $10 \mathrm{~mm} \sim 20 \mathrm{~mm}$ larger than the diameter of drill pipe, so the diameter of hole space was set to be $93.5 \mathrm{~mm}$. In addition, it needs a zone for the creation of coal slag, so the depth of hole space was set to be $1008 \mathrm{~mm}$.
According to the parameters in Table 1, the drill pipe model and drill hole model were established, as shown in Figure 3.

3.2. Grid Division. The quality of meshing directly affects the simulation results. This article uses the Ansys Workbench to preprocess the 3D model. The Design Modeler module was used to extract the inner flow passage of the slag discharge channel that needs to be numerically simulated in the model, and the extracted flow passage is shown in Figure 4.

Because of the complexity of fluid movement in slag discharge process, in order to depict the flow path of fluid more realistically, the tetrahedral meshing method was used to divide the meshing. The gird generation is shown in Figure 5.

According to the model characteristics, different classification methods were used for different locations of the model. The slag discharge channel model includes three parts: the airflow inlet channel in the middle of the drill pipe, the bottom of the drill hole, the annular channel formed by the outer surface of the drill pipe, and the drill hole.

(a) The middle passage of the drill pipe is cylinder, which is the passage for compressed airflow to enter the bottom of the hole. Because this part only exists in gas phase and has little influence on the numerical simulation results, we meshed this part by larger size to improve the simulation speed.

(b) The bottom of the hole is a cylindrical structure formed between the end of the drill pipe and the bottom of the hole. In the simulation process, the coal slag is generated in this part and is fully mixed with the compressed airflow after being subjected to the drag force from airflow. Therefore, tetrahedral mesh was used to divide the bottom region where gas-solid two phases fully interact. And the mesh of this part should be denser than that of the middle passage.

(c) Annular channel is similar to the toroidal structure, and the difference between them is that whorl exists in the inner part of the toroidal structure. In the simulation process, the mixture of compressed airflow and coal slag particles flows through this area quickly and flows out of the hole. The simulation of this part is the most important in the whole simulation, so this part was mesh by unstructured tetrahedral structure. Mesh division is as close as possible within the scope of computer computing power to ensure the accuracy and reliability of calculation results.

\section{Gas-Solid Two-phase Flow Coupling Methodology}

In the early stage of numerical simulation of fluid-solid coupling, the main method was mixing the fluid phase and the solid phase into a fluid with a different density than the original fluid phase [26]. However, limited by the function of CFD software, the flow state and motion rule of particle 


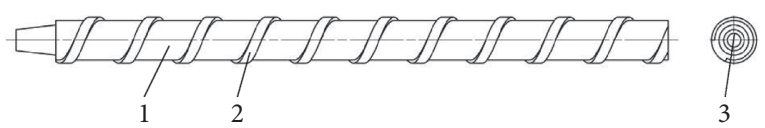

FIgURE 1: Sketch of rib drill ripe.

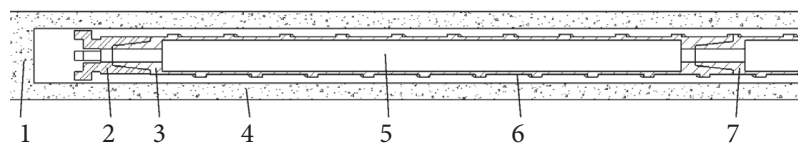

FIGURE 2: Sketch of slag discharge channel of rib drill pipe.

TABle 1: Structural parameters of rib drill pipe.

\begin{tabular}{lc}
\hline Structure parameter & Value $(\mathrm{mm})$ \\
\hline Outer diameter & 63.5 \\
Inner diameter & 53.5 \\
Blade width & 18 \\
Blade height & 5 \\
Pitch & 96 \\
\hline
\end{tabular}

phase can only be judged by the change of fluid concentration and concentration gradient. In order to obtain better particle phase simulation results, the calculation module of discrete element software Edem is used to process the particle phase in the multiphase flow model [27]. EdemFluent coupled platform is used to simulate and analyze the slag discharge process of the rib-drill pipe in this paper. The advantage of this coupling method is that both gas phase and particle phase can be simulated at the same time. And the whole simulation process can be more similar to the actual slag discharge process by parameter setting specifically. There are more ways to process the simulation results, and it is easy to find the desired information from the simulation results.

4.1. Flow Theory of Gas-Solid Coupling. The continuity equation of fluid phase and Navier-Stokes equation are as follows:

$$
\begin{gathered}
\frac{\partial \rho}{\partial t}+\frac{\partial \rho u_{i}}{\partial x_{j}}=0 \\
\rho \frac{\partial u_{i}}{\partial t}+\rho u_{j} \frac{\partial u_{i}}{\partial x_{j}}=\mu \frac{\partial}{\partial x_{i}}\left(\frac{\partial u_{i}}{\partial x_{j}}+\frac{\partial u_{j}}{\partial x_{i}}\right)+\nabla P+\rho g+S .
\end{gathered}
$$

In the formula, $\rho$ is the fluid density, $\mathrm{kg} / \mathrm{m}^{3} ; U$ is the fluid velocity, $\mathrm{m} / \mathrm{s} ; \mu$ is hydrodynamic viscosity, $\mathrm{Pa} \cdot \mathrm{s} ; P$ is gas pressure, $\mathrm{Pa} ; g$ is the acceleration of gravity, $\mathrm{m} / \mathrm{s}^{2} ; S$ is the quantity exchange source phase.

The subscripts $i$ and $j$ in the two equations indicate the direction, and in the three-dimensional cartesian coordinate system, $i, j=1,2,3$. Repeat the subscript to denote the Einstein summation convention.

Navier-Stokes equations are used to calculate the drag force between the gas phase and the particle phase and realize the coupling between them by the momentum exchange source. The motion of the particle phase in the coupled simulation follows Newton's second law:

$$
m_{i} \frac{\mathrm{d} v_{i}}{\mathrm{~d} t}=m_{i} g+\left(F_{d}\right)_{i}-\left(V_{P}\right)_{i} \nabla P_{i}
$$

Here, $m_{i}$ is mass, $\mathrm{kg} ; v_{i}$ is velocity, $\mathrm{m} / \mathrm{s} ;\left(V_{P}\right)_{i}$ is the volume, $\mathrm{m}^{3} ;\left(F_{d}\right)_{i}$ is drag force, $\mathrm{N} ; \nabla P_{i}$ is pressure gradient, $\mathrm{MPa} / \mathrm{m}$.

4.2. Gas-Solid Two-Phase Flow Model Selection. The calculation method of particle phase is the key to the gas-solid two-phase flow problem.

In the actual slag discharge process of rib drill pipe during drilling construction, the slag discharge airflow will discharge the coal slag through the slag discharge channel formed between drill pipe and hole wall [28]. The airflow in the slag discharge channel can be regarded as the gas phase and the coal slag particles can be regarded as the solid phase, so the whole slag discharge flow process can be regarded as the gas-solid two-phase flow model [29]. Gas-solid twophase flow can be divided into dilute gas-solid two-phase flow and dense gas-solid two-phase flow. In the process of slag discharge, the density of particle phase is relatively large, and the collision force between coal slag particles cannot be ignored, so the slag discharge process of rib drill pipe can be considered as dense gas-solid two-phase flow [30].

4.3. Edem-Fluent Coupling Method. Edem and Fluent were used for coupling numerical simulation, and Edem and Fluent were used for the calculations of particle phase and gas phase, respectively. The realization of mass, momentum, and energy exchange between two phases mainly relies on the following two coupling methods: Eulerian-Lagrangian method [31] and Eulerian-Eulerian method [32]. EulerianLagrangian method is applicable to dilute gas-solid twophase flow with a solid volume fraction less than $10 \%$. This method only includes momentum exchange between two phases. Eulerian-Eulerian method is applicable to dense gassolid two-phase flows with a large volume fraction. In addition, this method also considers the reaction force of particles relative to the gas phase and the exchange of mass, momentum, and energy between the two phases, and the calculation speed is relatively slow due to the large amount of calculation. In the process of drilling slag discharge, collisions often occur and the collision mode is complex, so the Eulerian-Eulerian method was chosen for coupling simulation.

4.4. Contact Mechanics Model Selection. The premise of obtaining the correct motion state of the coal slag is the accuracy of the force between the coal slags during the simulation process. Two characteristics of slag discharge simulation process will affect the select of contact mechanics model. The first one is that the coal slag particles are hard and do not have significant deformation during contact. The second one is that the slag discharge medium is airflow, and 


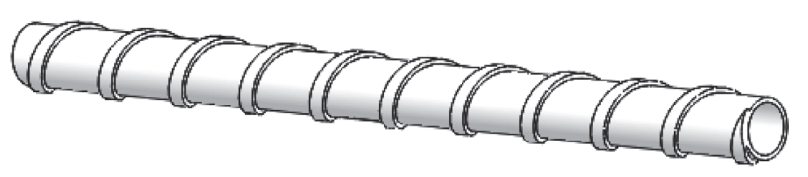

(a)

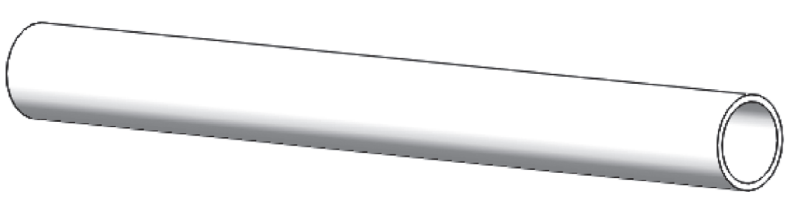

(b)

(c)

Figure 3: Model of slag discharge. (a) Drill pipe. (b) Hole space. (c) Combined model.

FIGURE 4: Flow model of interior of slag discharge process.

the coal slag particles are hard to bond in this dry environment. According to the above characteristics, HertzMindlin nonsliding contact model which focuses on the contact force between particles was selected. It is suitable for the numerical simulation which studies the interaction force between coal slag particles and the motion track of coal slag particles in the slag discharge process.

4.5. Calculation Method of Simulation Time Step. Rayleigh wave method is usually used to get the appropriate time step in the discrete element method. The calculation formula of Rayleigh wave velocity and time step is shown as follows:

$$
v_{R}=(0.163 v+0.877) \sqrt{\frac{G}{\rho}} .
$$

In the formula, $v$ is Poisson's ratio; $G$ is the shear modulus of the particle, $\mathrm{Pa} ; \rho$ is the density of the particle, $\mathrm{kg} / \mathrm{m}^{3}$.

$$
t_{R} \leq \frac{\pi R}{v_{R}}=\frac{\pi R}{0.163 v+0.877} \sqrt{\frac{G}{\rho}}
$$

Here, $R$ is the radius of the particle, $m$.

The time step is usually chosen to be $5 \% \sim 30 \%$ of the time needed for the distance of the hemispherical surface of the particles to be transmitted by the Rayleigh wave. Because the difference in time step between Edem and Fluent used separately, we need match time step before the co-simulation. The matching requirements are as follows:

(a) The time step of Edem should be less than the time step of Fluent and must be within the range of 5\% $30 \%$ of Rayleigh step (b) The time step of Fluent ensures that the calculation of fluid part converges

(c) The time step of Fluent should be an integer multiple of the time step of Edem, and the multiple is between 10 and 100 usually

\section{Edem-Fluent Joint Simulation}

5.1. Boundary Conditions Simulation Parameters. Solvers in Fluent re mainly divided into two categories: one is the density base solver mainly used for compressible gas flow, and the other is the pressure base solver mainly used for incompressible fluid and medium compressible fluid. The pressure base solver is also suitable for the coupled simulation of multiphase flow. Based on the above assumption that the slag discharge fluid is an incompressible gas, this simulation selected the pressure base solver [33].

Set the boundary conditions according to the actual working conditions. The airflow rate was set to $3 \mathrm{~m}^{3} / \mathrm{min}$, and the flow velocity of inlet was set to $22.2 \mathrm{~m} / \mathrm{s}$. After further calculation, the Reynolds number of the inlet is $8.025^{*} 104$, the hydraulic diameter is $53.5 \mathrm{~mm}$, and the empirical constant is 0.09 . Other inlet boundary conditions are shown in Table 2.

The outlet boundary is the pressure outlet, and the environmental pressure was set to $1.013 \mathrm{MPa}$. The moving reference system model was used to simulate the rotary motion of the drill pipe, and the airflow in the blade clearance of drill pipe was defined to rotate at the same speed with the drill pipe, and the speed was set to be $150 \mathrm{rad} / \mathrm{min}$. SIMPLEC algorithm is used for velocity-pressure coupling calculation because it is suitable for tetrahedral meshing.

5.2. Simulation Parameters Setting. In the process of numerical simulation, the material of particle and hole wall is coal, and the material of drill pipe is steel. Material parameters and contact parameters in Edem were determined by referring to relevant data [34], as shown in Table 3.

In the drilling process, the calculation formula of coal slag mass produced by the drill bit is shown as follows:

$$
Q=\frac{\pi R_{h}^{2} V \rho_{m}}{\eta} .
$$


TABLE 2: Inlet boundary conditions.

\begin{tabular}{lc}
\hline Inlet parameters & Inlet boundary condition value \\
\hline Turbulence intensity & 0.039 \\
Turbulence length dimension & $2.675 \mathrm{~mm}$ \\
Turbulent kinetic energy & 1.12 \\
Turbulent dissipation energy & 52.01 \\
\hline
\end{tabular}

Here, $R_{h}$ is the radius of hole space, $m ; V$ is the rate of penetration of drill pipe, $\mathrm{m} / \mathrm{s} ; \rho_{m}$ is the density of coal, $\mathrm{kg} / \mathrm{m}^{3} ; \eta$ is the bulking coefficient, and its value range is $0.3 \sim 0.5$.

According to the rate of penetration of drill pipe during drilling, the coal slag formation rate of particle factory was set to $0.08 \mathrm{~kg} / \mathrm{s}$. The initial velocity of coal slag was set to $0 \mathrm{~m} /$ $s$, and the generated position was set on the entire circular surface at the bottom of the borehole. The particle size was set within the range of $0.5 \mathrm{~mm}$ to $1 \mathrm{~mm}$ [35]. The time step was set to $1 E^{-6} \mathrm{~s}$, which is $24.01 \%$ of Rayleigh time step. The time step of Fluent was selected to $5 E^{-5} \mathrm{~s}$, which conforms to the selection principle of time step of Edem-Fluent coupling. The drill pipe model was set to rotate around its own axis, and the rotation speed is consistent with the moving mesh in Fluent.

The convergence accuracy was set to $1 E^{-3}$ in Fluent. The residual curve was calculated as shown in Figure 6. It can be found that the residual curve fluctuates periodically within the normal range. Through flow monitoring, it can be found that the mass flow error between the inlet and outlet of the slag discharge channel is less than $0.1 \%$, so as to judge that the calculation of the whole system has reached convergence.

In order to make the numerical simulation results more accurate, the mesh division of the slag discharge channel model is very dense, and the values of residual convergence precision and time step size in Fluent are very small. But this also makes the simulation process very slow. Through the observation of the fluid pressure and velocity changes during the numerical simulation, it was found that the entire slag discharge model reaches a relatively stable state at $0.2 \mathrm{~s}$. After this time, the pressure and velocity in the slag discharge channel were basically stable, and the slag discharge ability of the whole model was reflected, so the iterative step number of numerical simulation was set to $2 E^{+04}$. The simulation analysis results are shown in Figure 7.

\section{Orthogonal Experiment on Drill Pipe Structure}

We chose the orthogonal experimental method as the tool to find the optimal solution and structural optimization. The test scheme is determined by querying the orthogonal table, and then the results after the test are processed. The experimental data obtained by orthogonal experiment have the characteristics of high reliability and high quality [36]. (Figure 7)

The structural parameters to be optimized include pitch, blade height, and blade width by observing the simulation results of original drill pipe. A level table of simulation factors is established, as shown in Table 4.
TABLE 3: Material parameters and contact parameters.

\begin{tabular}{lcc}
\hline Material parameters & Coal & Steel \\
\hline Density & $1400 \mathrm{~kg} / \mathrm{m}^{3}$ & $7800 \mathrm{~kg} / \mathrm{m}^{3}$ \\
Poisson's ratio & 0.3 & 0.3 \\
Shear modulus & $2 e+02 \mathrm{MPa}$ & $1 e+04 \mathrm{MPa}$ \\
\hline Contact parameters & Coal-coal & Coal slag-drill pipe \\
\hline Coefficient of restitution & 0.5 & 0.5 \\
Coefficient of static friction & 0.6 & 0.4 \\
Coefficient of rolling friction & 0.05 & 0.05 \\
\hline
\end{tabular}

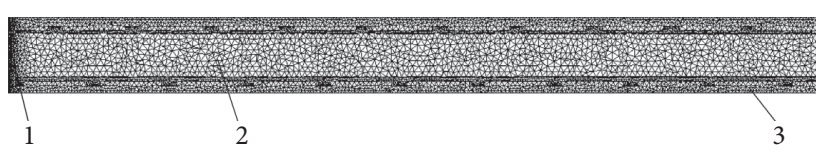

FIgURE 5: Meshing of slag discharge channel.

Consider the number of factors and levels, $L_{25}\left(5^{4}\right)$ was selected to carry out the orthogonal experimental design of 3 factors and 5 levels. Column 4 was set as the error term to check if there have been interaction terms in the orthogonal table. The quality of coal slag discharged within $0 \sim 1 \mathrm{~s}$ was taken as the orthogonal experimental evaluation standard, and the significance of structural parameters was sorted according to the range difference $R$ of each factor, and the optimal level number of each factor was selected (Table 5). The simulation result as shown in Table 5.

As shown in Table 6, by comparing the range values in the table, it can be concluded that the order of significance of each factor that affected the evaluation index is blade height, pitch, and blade width. The significance of the error term ranked last, which can prove that there is no interaction effect among various factors in $L_{25}\left(5^{4}\right)$ orthogonal table, and the horizontal selection of each factor is appropriate. By comparing the $K_{i}$ of each factor in the table, it can be concluded that the optimal horizontal combination is pitch, blade height, and blade width being $120 \mathrm{~mm}$, $3 \mathrm{~mm}$, and $15 \mathrm{~mm}$, respectively. Since there is no such combination in the orthogonal table, it is necessary to reestablish the drill pipe model and carry out simulation verification according to the optimal horizontal combination.

Figure 8 shows the simulation results of optimized drill pipe model. Compared with the simulation results obtained by the original drill pipe model, it can be found that there are four main improvements:

(1) The pressure drop velocity gradient of the annular slag discharge channel decreases, and the pressure drop loss along the flow decreases, which is conducive to the slag discharge of the deeper hole.

(2) The $x$-direction velocity is the same as the direction of the slag discharge channel, so the velocity of flow in the annular channel is an important basis to investigate the capacity of slag discharge. After optimization, the continuity of $x$-velocity in the annular 


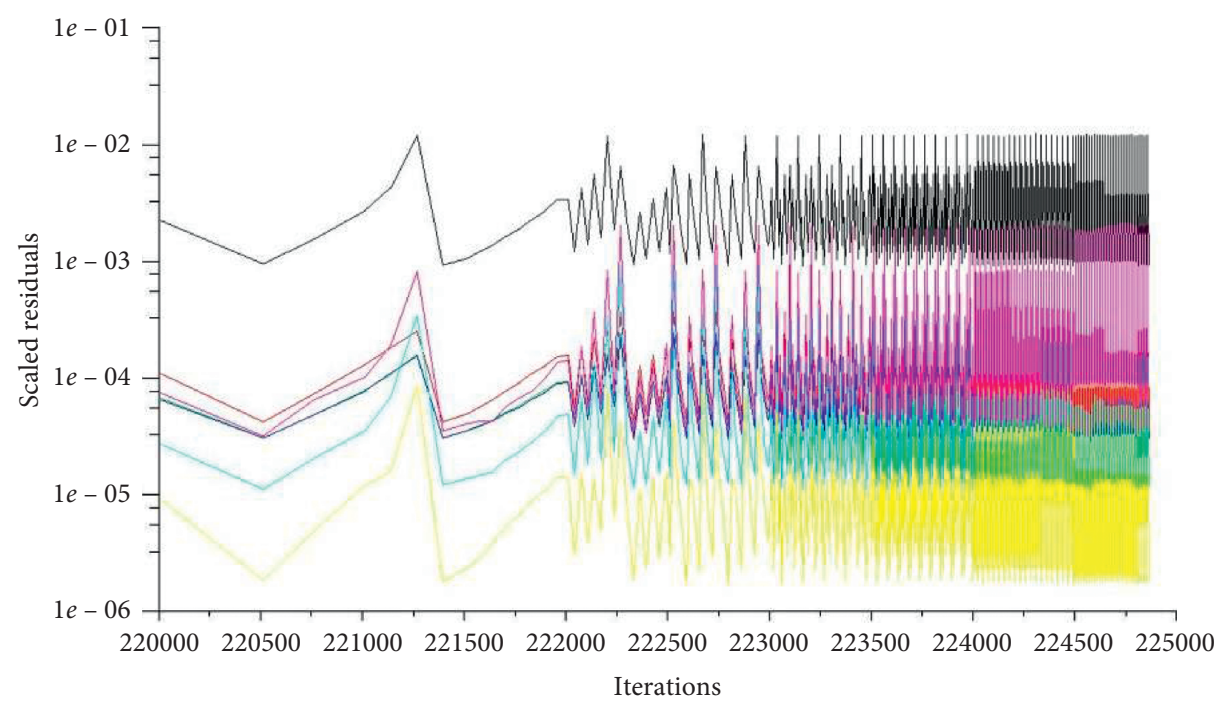

Residuals

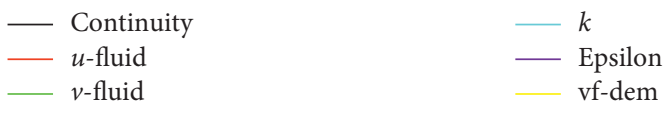

FIgURE 6: Residual curve.

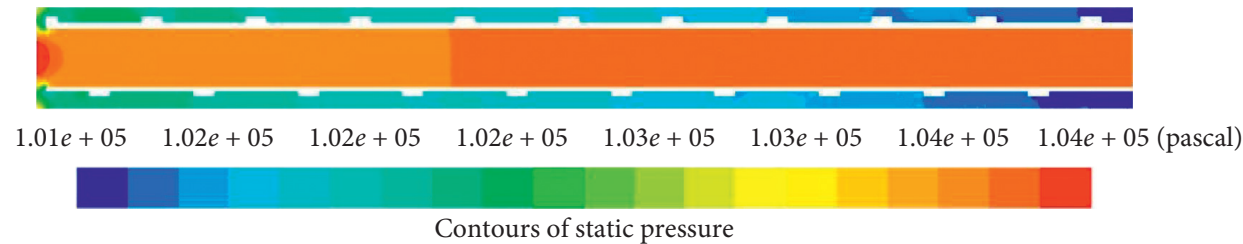

(a)

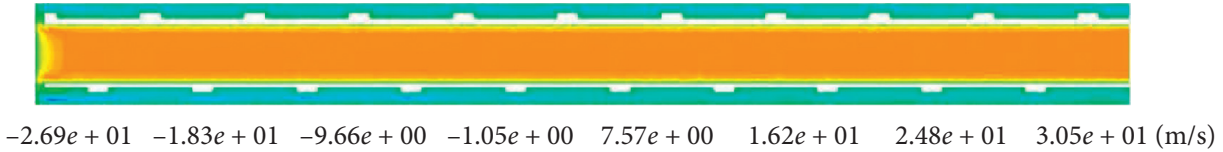

Contours of $X$ velocity

(b)
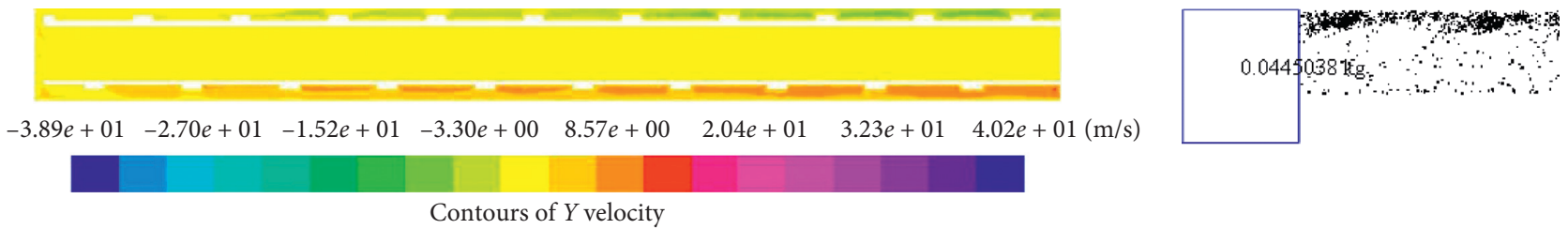

(c)

(d)

FIgURE 7: Simulation results of original drill pipe. (a) Nephogram of static pressure distribution for airflow migration. (b) Distribution nephogram of $X$ direction velocity of flow. (c) Distribution nephogram of $Y$ direction velocity of flow. (d) Mass of discharge slag. 
TABLE 4: Level of simulation factors.

\begin{tabular}{lccc}
\hline & & Factors & \\
Level & A pitch $(\mathrm{mm})$ & B blade height $(\mathrm{mm})$ & C blade width (mm) \\
\hline 1 & 80 & 3 & 15 \\
2 & 90 & 5 & 18 \\
3 & 100 & 7 & 21 \\
4 & 110 & 9 & 21 \\
5 & 120 & 11 & 27 \\
\hline
\end{tabular}

TABLE 5: Simulation result.

\begin{tabular}{|c|c|c|c|c|c|}
\hline \multirow[b]{2}{*}{ Level } & \multicolumn{5}{|c|}{ Factor } \\
\hline & A pitch $(\mathrm{mm})$ & B blade height $(\mathrm{mm})$ & C blade width $(\mathrm{mm})$ & Error term & Total slag mass $(\mathrm{kg})$ \\
\hline 1 & 80 & 3 & 15 & 1 & 0.0440074 \\
\hline 2 & 80 & 5 & 27 & 2 & 0.0403255 \\
\hline 3 & 80 & 7 & 24 & 3 & 0.0379504 \\
\hline 4 & 80 & 9 & 21 & 4 & 0.0333134 \\
\hline 5 & 80 & 11 & 18 & 5 & 0.033125 \\
\hline 6 & 90 & 3 & 27 & 4 & 0.0442399 \\
\hline 7 & 90 & 5 & 24 & 5 & 0.0427634 \\
\hline 8 & 90 & 7 & 21 & 1 & 0.0419654 \\
\hline 9 & 90 & 9 & 18 & 2 & 0.034878 \\
\hline 10 & 90 & 11 & 15 & 3 & 0.0333134 \\
\hline 11 & 100 & 3 & 24 & 5 & 0.0465584 \\
\hline 12 & 100 & 5 & 21 & 1 & 0.0439257 \\
\hline 13 & 100 & 7 & 18 & 2 & 0.0399736 \\
\hline 14 & 100 & 9 & 15 & 3 & 0.0375672 \\
\hline 15 & 100 & 11 & 27 & 4 & 0.032415 \\
\hline 16 & 110 & 3 & 21 & 3 & 0.0470359 \\
\hline 17 & 110 & 5 & 18 & 4 & 0.0463071 \\
\hline 18 & 110 & 7 & 15 & 5 & 0.0448431 \\
\hline 19 & 110 & 9 & 27 & 1 & 0.0418586 \\
\hline 20 & 110 & 11 & 24 & 2 & 0.034702 \\
\hline 21 & 120 & 3 & 18 & 2 & 0.0473878 \\
\hline 22 & 120 & 5 & 15 & 3 & 0.0474946 \\
\hline 23 & 120 & 7 & 27 & 4 & 0.0427634 \\
\hline 24 & 120 & 9 & 24 & 5 & 0.0429393 \\
\hline 25 & 120 & 11 & 21 & 1 & 0.0410229 \\
\hline
\end{tabular}

TABLE 6: Result of range method.

\begin{tabular}{|c|c|c|c|c|}
\hline K1 & 0.1887217 & 0.2292294 & 0.2072757 & 0.20278 \\
\hline $\mathrm{K} 2$ & 0.1971601 & 0.2208163 & 0.2016715 & 0.198267 \\
\hline K3 & 0.2004399 & 0.2074959 & 0.2072633 & 0.203362 \\
\hline K4 & 0.2147467 & 0.1905565 & 0.2049135 & 0.199039 \\
\hline K5 & 0.221608 & 0.1745783 & 0.2016024 & 0.200229 \\
\hline $\mathrm{k} 1$ & 0.03774434 & 0.04584588 & 0.04144514 & 0.040556 \\
\hline $\mathrm{k} 2$ & 0.03943202 & 0.04416326 & 0.0403343 & 0.0396534 \\
\hline $\mathrm{k} 3$ & 0.04008798 & 0.04149918 & 0.04145266 & 0.0406724 \\
\hline $\mathrm{k} 4$ & 0.04294934 & 0.0381113 & 0.0409827 & 0.0398078 \\
\hline $\mathrm{k} 5$ & 0.0443216 & 0.03491566 & 0.04032048 & 0.0400458 \\
\hline Range & 0.00657726 & 0.01093022 & 0.00113218 & 0.0010190 \\
\hline Primary and secondary factors & B & $\mathrm{A}$ & $\mathrm{C}$ & $\mathrm{E}$ \\
\hline Optimal solution & A5 & B1 & $\mathrm{C} 1$ & E3 \\
\hline
\end{tabular}

passage of the drill pipe is improved obviously, and a more stable coal slag migration zone is generated.

(3) The $y$-direction velocity is generated by the spiral flow around the drill pipe under the influence of the blades. The spiral flow can expel the coal slag, but it need spend some energy to overcome the gravitational potential energy. The route length of spiral slag discharge is much longer than that of linear slag 


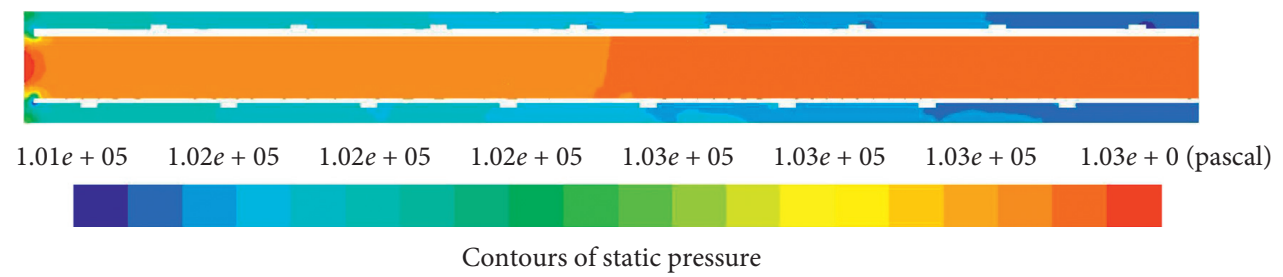

(a)

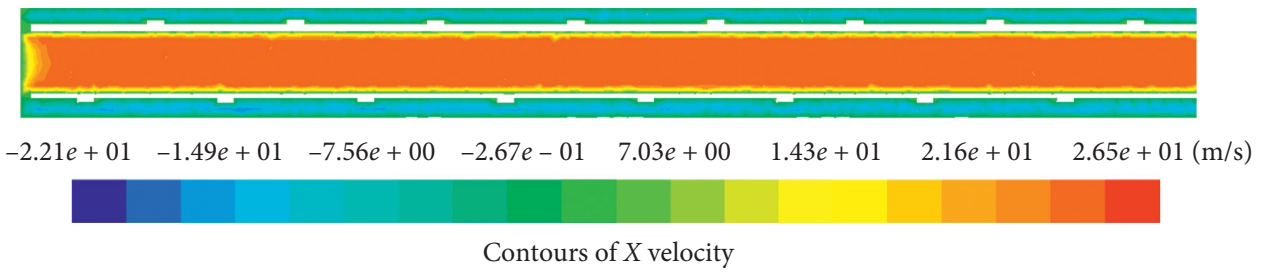

(b)

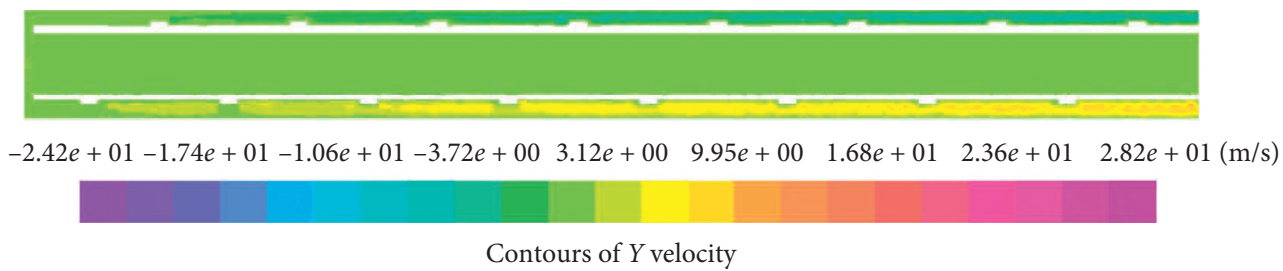

(c)

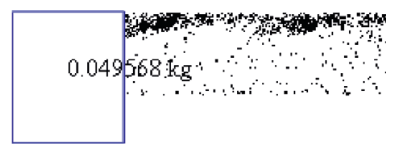

(d)

FIGURE 8: Simulation results of optimized drill pipe. (a) Nephogram of static pressure distribution for airflow migration. (b) Distribution nephogram of $X$ direction velocity of flow. (c) Distribution nephogram of $Y$ direction velocity of flow. (d) Mass of discharge slag.

discharge, so the spiral flow will reduce slag discharge efficiency and is easy to cause slag obstruction. The optimized drill pipe can effectively inhibit the generation of spiral flow and is more conducive to the formation of linear slag discharge mode.

(4) The total mass of coal slag discharged from the optimized drill pipe reached $0.049568 \mathrm{~kg}$ within $0 \sim 1 \mathrm{~s}$, which was $11.38 \%$ higher than that of the original drill pipe. It is also greater than the evaluation index of all experimental schemes in the orthogonal table.

\section{Conclusions}

(1) In order to find out the deficiency in the slag discharge process of rib drill pipe, the $3 \mathrm{D}$ model of the slag discharge process was established based on the actual working conditions for simulation.

(2) Based on the mechanism of slag discharge process of rib drill pipe, the slag discharge process was simplified as the gas-solid two-phase flow coupling process with CFD, and the gas-solid coupling model of drilling slag discharge was established. Furthermore, the numerical simulation on drilling slag discharge was carried out with Edem-Fluent joint simulation. The parameters of rib drill pipe that need to be optimized were obtained according to the simulation results.
(3) In order to optimize the rib drill pipe, the optimal parameters combination was obtained with the orthogonal experiment method. The optimum structure rig drill pipe was established based on optimal parameters combination. The numerical simulation for optimum structure rig drill pipe was carried out and it is found that the slag discharge efficiency is increased by $11.38 \%$. The optimum structure rig drill pipe reduces the possibility of pipe-sticking caused by coal slag blockage.

\section{Data Availability}

The data used to support the findings of this study are included within the article.

\section{Conflicts of Interest}

The authors declare that they have no conflicts of interest.

\section{Acknowledgments}

The authors would like to acknowledge Project of Shandong Province Higher Educational Science and Technology Program, China (J18KB020), and Key Research and Development Plan of Shandong Province, China (2019GGX104102).

\section{References}

[1] Y.-K. Ma, B.-S. Nie, X.-Q. He, X.-C. Li, J.-Q. Meng, and D.-Z. Song, "Mechanism investigation on coal and gas 
outburst: an overview," International Journal of Minerals, Metallurgy and Materials, vol. 27, no. 7, pp. 872-887, 2020.

[2] L. Hong, D. Gao, J. Wang, and D. Zheng, "The power source for coal and gas outburst," Journal of Mining Science, vol. 55, no. 2, pp. 239-246, 2019.

[3] A.-T. Zhou, M. Zhang, K. Wang, D. Elsworth, J.-W. Wang, and L.-P. Fan, "Airflow disturbance induced by coal mine outburst shock waves: a case study of a gas outburst disaster in China," International Journal of Rock Mechanics and Mining Sciences, vol. 128, Article ID 104262, 2020.

[4] L.-M. Xu, K.-X. Lu, Y.-S. Pan, and Z.-J. Qin, "Study on rock burst characteristics of coal mine roadway in China," Energy Sources, Part A: Recovery, Utilization, and Environmental Effects, vol. 2019, pp. 1556-7036, 2019.

[5] X.-Z. Li and A.-Z. Hua, "Prediction and prevention of sandstone-gas outbursts in coal mines," International Journal of Rock Mechanics and Mining Sciences, vol. 43, no. 1, pp. 2-18, 2006.

[6] R. Zhang, Y.-P. Cheng, L. Yuan, H.-X. Zhou, L. Wang, and W. Zhao, "Enhancement of gas drainage efficiency in a special thick coal seam through hydraulic flushing," International Journal of Rock Mechanics and Mining Sciences, vol. 124, pp. 1365-1609, 2019.

[7] V. I. Klishin, V. N. Fryanov, L. D. Pavlova, and G. Y. Opruk, "Modeling top coal disintegration in thick seams in longwall top coal caving," Journal of Mining Science, vol. 55, no. 2, pp. 247-256, 2019.

[8] J. C. Wang, Z. H. Wang, and S. L. Yang, "Stress analysis of longwall top-coal caving face adjacent to the gob," International Journal of Mining, Reclamation and Environment, vol. 34, no. 7, pp. 476-497, 2020.

[9] S. Zhang, Y. Li, B. Shen, X. Sun, and L. Gao, "Effective evaluation of pressure relief drilling for reducing rock bursts and its application in underground coal mines," International Journal of Rock Mechanics and Mining Sciences, vol. 114, pp. 7-16, 2019.

[10] O. N. Malinnikova, E. V. Ul'yanova, A. V. Kharchenko, and B. N. Pashichev, "Influence of coal microstructure on gas content of the face area," Journal of Mining Science, vol. 56, no. 3, pp. 351-358, 2020.

[11] W.-Z. Cao, J.-Q. Shi, S. Durucan, G.-Y. Si, and A. Korre, "Gasdriven rapid fracture propagation under unloading conditions in coal and gas outbursts," International Journal of Rock Mechanics and Mining Sciences, vol. 130, Article ID 104325, 2020.

[12] J. Fang, Q.-X. Li, C. Xu, and J.-L. Liu, "Construction technology and development tendency of gas drainage borehole in soft and outburst seam," Coal Science and Technology, vol. 46, no. 5, pp. 130-137, 2018.

[13] S.-Q. Xiao, Q.-Y. Ren, Z.-L. Ge, B. Chen, and F.-F. Wang, "Study of the rock-breaking and drilling performance of a selfrotatory water-jet bit in water-jet drilling and its influential factors," Energy Sources, Part A: Recovery, Utilization, and Environmental Effects, vol. 2020, 2020.

[14] L. Wang, "Research and development on atomizer of air atomizeddrilling in soft seam of underground mine," Coal Science and Technology, vol. 44, no. 8, pp. 150-155, 2016.

[15] X.-S. Yin, J.-L. Liu, and Y. Liu, "Foam drilling technique by gas extraction drilling long borehole in soft coal seam," Safety In Coal Mines, vol. 44, no. 11, pp. 5-8, 2014.

[16] Q.-Q. Li, "Study on the optimal parameter for air casing drilling in underground coal mine," Safety in Coal Mines, vol. 526, no. 5, pp. 120-123, 2018.
[17] H. Hou, "Application of auger drilling technology with deep grooves and wide blades in soft coal seam," Coal Engineering, vol. 50, no. 5, pp. 68-70, 2018.

[18] Q.-X. Li, "Research and application of drilling technology combined rotary with direction in soft-fragmentized coal seam," Coal Science and Technology, vol. 46, no. 11, pp. 106-111, 2018.

[19] K. Dong, R. Zhu, W. Gao, and F.-H. Liu, "Simulation of threephase flow and lance height effect on the cavity shape," International Journal of Minerals, Metallurgy, and Materials, vol. 21, no. 6, pp. 523-530, 2014.

[20] A. T. Zhou, K. Wang, T. A. Kiryaeva, and V. N. Oparin, "Regularities of two-phase gas flow under coal and gas outbursts in mines," Journal of Mining Science, vol. 53, no. 3, pp. 533-543, 2017.

[21] B. Shao, Y. Yan, X. Wang, F. Liao, and X. Yan, "Numerical investigation of a double-circulation system for cuttings transport in CBM well drilling using a CFD-DEM coupled model," Engineering Applications of Computational Fluid Mechanics, vol. 14, no. 1, pp. 38-52, 2020.

[22] B. Shao, Y. Yan, X. Yan, and Z. Xu, "A study on non-spherical cuttings transport in CBM well drilling by coupled CFDDEM," Engineering Applications of Computational Fluid Mechanics, vol. 13, no. 1, pp. 579-590, 2019.

[23] M. Alihosseini and P. U. Thamsen, "Analysis of sediment transport in sewer pipes using a coupled CFD-DEM model and experimental work," Urban Water Journal, vol. 16, no. 4, pp. 259-268, 2019.

[24] C.-J. Wang and S.-Q. Yang, "Mechanism of dynamic phenomena of borehole for outburst prediction and their relationship during coal roadway driving," Journal of China Coal Society, vol. 42, no. 9, pp. 2327-2336, 2017.

[25] K. Wang, W.-L. Guo, G. Feng, X.-Q. Gong, and Y.-P. Xin, "Reasonable parameters simulation and study on dual-power drilling rod," Safety in Coal Mines, vol. 49, no. 3, pp. 105-108, 2018.

[26] Y.-L. Wang, Y.-N. Sun, C. Liu, Z.-H. He, and Z.-F. Wang, "The dynamic characteristic and application of drilling cuttings movement in "drilling cave" in soft coal seam drilling," Journal of Mining \& Safety Engineering, vol. 33, no. 6, pp. 1138-1144, 2016.

[27] M. R. Fatahi and A. Farzanegan, "An analysis of multiphase flow and solids separation inside Knelson concentrator based on four-way coupling of CFD and DEM simulation methods," Minerals Engineering, vol. 126, pp. 130-144, 2018.

[28] H.-W. Yang and Y.-L. Fan, "Application of high rotation speed compound slag drilling technology in complex coal seam," Coal Engineering, vol. 51, no. 3, pp. 50-53, 2019.

[29] K. Chu, J. Chen, and A. Yu, "Applicability of a coarse-grained CFD-DEM model on dense medium cyclone," Minerals Engineering, vol. 90, pp. 43-54, 2016.

[30] G.-S. Liu and H. Xu, "Modeling of gas-soild two-phase flow using kinetic theory," Journal of Combustion Science and Technology, vol. 3, no. 2, pp. 143-149, 1997.

[31] M. Askarishahi, M.-S. Salehi, and S. Radl, "Voidage correction algorithm for unresolved Euler-Lagrange simulations," Computational Particle Mechanics, vol. 5, no. 4, pp. 607-625, 2018.

[32] S. T. W. Kuruneru, E. Marechal, M. Deligant et al., "A comparative study of mixed resolved-unresolved CFD-DEM and unresolved CFD-DEM methods for the solution of particle-laden liquid flows," Archives of Computational Methods in Engineering, vol. 26, no. 4, pp. 1239-1254, 2019. 
[33] Z.-X. Li, T.-M. Wang, S.-Y. Wang, and Y.-D. Wang, "Simulation study of ventilation system disaster evolution in coal and gas outburst mine," Journal of China Coal Society, vol. 42, no. 4, pp. 929-934, 2017.

[34] J. Mao, X.-Y. Liu, H.-Y. Chen, and Q.-S. Song, "Simulation of shearer drum cutting performance based on EDEM," Journal of China Coal Society, vol. 42, no. 4, pp. 1069-1077, 2017.

[35] S. Hu, L.-Y. Shan, B.-Y. Xu, J.-L. Su, and Y. Wang, "Mesomechanical properties evolution during fracture of coal cubes under loading," Journal of China Coal Society, vol. 43, no. 3 , pp. 855-861, 2018.

[36] X.-L. Liu, M.-M. Wang, X.-Y. Wang, J.-X. Yu, and J.-Q. Guo, "Numerical analysis on stability of deep rock roadway based on orthogonal test," Coal Science and Technology, vol. 46, no. 2, pp. 138-143, 2018. 